\title{
Inherent Selectivity of Pd C-H Activation from Different Metal Oxidation States
}

\author{
Peter Amadeo, ${ }^{[a]}$ Bangaru Bhaskararao, ${ }^{[a]}$ Yun-Fang Yang, ${ }^{[b]}$ and Marisa C. Kozlowski*[a] \\ E-mail: marisa@sas.upenn.edu \\ [a] Department of Chemistry, University of Pennsylvania, Philadelphia, Pennsylvania 19104, United States. \\ [b] College of Chemical Engineering, Zhejiang University of Technology, Hangzhou, Zhejiang 310014, China.
}

Computational Methods

Tables of Computed Energies

Coordinates and Thermochemical Values
S2

S2

S3-S26 
Computational Methods: All geometry optimizations and transition state structures were calculated using the UB3LYP functional in Gaussian 16C.01 with split basis set (6-31G* for C, H, N, O and LANL2DZ for $\mathrm{Pd}$ ) in the gas phase. Frequency calculations were carried out at the same level of theory to obtain thermal corrections (at $298 \mathrm{~K}$ ) and to confirm local minima (via the absence of imaginary frequencies) or saddle points (via the presence of one and only one imaginary frequency). Conformational space was explored to determine global minima through successive dihedral scans at the same level of theory. Single-point calculations were carried out on optimized structures in toluene using the SMD solvation model, the uM06 functional, and split basis set $\left(6-311+\mathrm{G}^{* *} \mathrm{C}, \mathrm{H}, \mathrm{N}, \mathrm{O}\right.$ and LANL2DZ for Pd). Obtained single-point energies were converted to the enthalpies and Gibbs free energies using corrections from gas-phase frequency analysis.

Distortion-Interaction Analysis (Activation Strain Model):

$\mathrm{E}_{\mathrm{act}}=\mathrm{E}_{\text {interaction(i) }}+\mathrm{E}_{\text {distortion(d) }}$

$\mathrm{f} 1=\mathrm{Pd}$-ligand and $\mathrm{f} 2=$ toluene

$E_{d}=\left\{\left(E_{f 1(T S)}+E_{f 2(T S)}\right)-\left(E_{f 1}+E_{f 2}\right)\right\}$

$E_{i}=\left\{\left(E_{(T S)}-\left(E_{f 1(T S)}+E_{f 2(T S)}\right)\right.\right.$

Table S1. Relative Gibbs free energy of the $\mathrm{C}-\mathrm{H}$ activation transition states $\left(\Delta \mathrm{G}^{\ddagger}=\mathrm{sp} 2 / \mathrm{sp} 3\right)$ and Gibbs free energy of the reaction $\left(\Delta \mathrm{G}^{\circ}\right)$ or respective products using the toluene and $\mathrm{Pd}$ catalyst calculated at the M06/6-31G*/LANL2DZ level of theory.

\begin{tabular}{|c|c|c|c|c|c|}
\hline & $\Delta \mathrm{G}^{\ddagger}(\mathrm{C} \ldots \mathrm{H}$ TS $)$ & $\Delta \mathrm{G}^{\circ} /$ product & & $\Delta \mathrm{G}^{\ddagger}(\mathrm{C} \ldots \mathrm{H} \mathrm{TS})$ & $\Delta \mathrm{G}^{\circ}$ \\
\hline $\mathrm{Pd}(0)-\mathrm{sp} 2$ & 10.8 & 10.7 & $\mathrm{Pd}(0)-\mathrm{sp3}$ & 8.5 & 5.4 \\
\hline & & & & & \\
\hline $\mathrm{Pd}(1)-\mathrm{sp} 2$ & 6.8 & 2.8 & $\mathrm{Pd}(1)$-sp3 & 4.3 & -3.9 \\
\hline & & & & & \\
\hline $\mathrm{Pd}(2)-\mathrm{sp2}$ & 18.1 & 4.2 & $\mathrm{Pd}(2)-\mathrm{sp3}$ & 26.1 & -6.2 \\
\hline & & & & & \\
\hline $\mathrm{Pd}(3)-\mathrm{sp2}$ & 23.9 & -13.4 & $\mathrm{Pd}(3)-\mathrm{sp3}$ & 31.4 & -19.0 \\
\hline
\end{tabular}

Table S2. Relative Gibbs Free energy of the $\mathrm{C}-\mathrm{H}$ activation transition states $\left(\Delta \mathrm{G}^{\ddagger}=\mathrm{sp} 2 / \mathrm{sp} 3\right)$ and Gibbs free energy of the reaction $\left(\Delta \mathrm{G}^{\circ}\right)$ or respective products using the toluene and $\mathrm{Pd}$ catalyst calculated at the B3LYP/6-31G*/LANL2DZ Level of Theory.

\begin{tabular}{|c|c|c|c|c|c|}
\hline & $\Delta \mathrm{G}^{\ddagger}$ (C...H TS) & $\Delta \mathrm{G}^{\circ} /$ product & & $\Delta \mathrm{G}^{\ddagger}(\mathrm{C} \ldots \mathrm{H} \mathrm{TS})$ & $\Delta \mathrm{G}^{\circ}$ \\
\hline $\mathrm{Pd}(0)$-sp2 & 9.7 & 6.1 & $\mathrm{Pd}(0)$-sp3 & 10.3 & 2.2 \\
\hline & & & & & \\
\hline $\mathrm{Pd}(1)$-sp2 & 13.3 & 9.2 & $\mathrm{Pd}(1)$-sp3 & 15.9 & 8.4 \\
\hline & & & & & \\
\hline $\mathrm{Pd}(2)$-sp2 & 23.1 & 13.3 & $\mathrm{Pd}(2)$-sp3 & 38.8 & 6.1 \\
\hline & & & & & \\
\hline $\mathrm{Pd}(3)$-sp2 & 34.2 & -1.0 & $\mathrm{Pd}(3)$-sp3 & 44.1 & -8.0 \\
\hline & & & & & \\
\hline
\end{tabular}

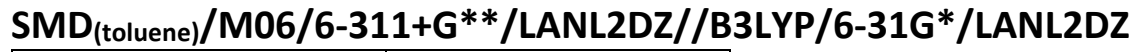

Total Energy 


\begin{tabular}{|l|l|}
\hline Toluene & -271.4154095 \\
\hline Pd0_HOAc & -355.7707478 \\
\hline Pd0_sp2_product & -627.1809478 \\
\hline Pd0_sp2_TS & -627.1800606 \\
\hline Pd0_sp3_product & -627.1907854 \\
\hline Pd0_sp3_TS & -627.1861506 \\
\hline Pd1_HOAc-OAc & -584.2120872 \\
\hline Pd1_sp2_proudct & -855.6361986 \\
\hline Pd1_sp2_TS & -855.6243858 \\
\hline Pd1_sp3_product & -855.6440291 \\
\hline Pd1_sp3_TS & -855.6290231 \\
\hline Pd2_2-OAc & -583.6080833 \\
\hline Pd2_sp2_product & -855.0404561 \\
\hline Pd2_sp2_TS & -855.0103085 \\
\hline Pd2_sp3_product & -855.0640405 \\
\hline Pd2_sp3_TS & -855.005056 \\
\hline Pd3_3-OAc_1 & -811.9937216 \\
\hline Pd3_sp2_product & -1083.450129 \\
\hline Pd3_sp2_TS & -1083.387747 \\
\hline Pd3_sp3_product & -1083.467957 \\
\hline Pd3_sp3_TS & -1083.378535 \\
\hline
\end{tabular}

$\mathrm{AcOH}$

Number of imaginary frequencies : 0

Electronic energy: $\quad=-229.0874077$

Zero-point correction $=\quad 0.062007$

Thermal correction to Energy= $\quad 0.066563$

Thermal correction to Enthalpy= $\quad 0.067507$

Thermal correction to Gibbs Free Energy $=0.034855$

Sum of electronic and zero-point Energies $=\quad-229.025400$

Sum of electronic and thermal Energies $=\quad-229.020845$

Sum of electronic and thermal Enthalpies $=\quad-229.019901$

Sum of electronic and thermal Free Energies $=\quad-229.052552$

Toluene

Number of imaginary frequencies : 0 
Electronic energy: $\quad=-271.5610831$

Zero-point correction $=\quad 0.128345$

Thermal correction to Energy $=\quad 0.134566$

Thermal correction to Enthalpy= $\quad 0.135510$

Thermal correction to Gibbs Free Energy $=0.097525$

Sum of electronic and zero-point Energies= $\quad-271.432738$

Sum of electronic and thermal Energies $=\quad-271.426517$

Sum of electronic and thermal Enthalpies= $\quad-271.425573$

Sum of electronic and thermal Free Energies $=\quad-271.463558$

PdO_HOAc

Number of imaginary frequencies : 0

Electronic energy: $\quad=-355.8115598$

Zero-point correction $=\quad 0.062230$

Thermal correction to Energy $=\quad 0.068616$

Thermal correction to Enthalpy= $\quad 0.069561$

Thermal correction to Gibbs Free Energy $=\quad 0.029984$

Sum of electronic and zero-point Energies $=\quad-355.749329$

Sum of electronic and thermal Energies $=\quad-355.742943$

Sum of electronic and thermal Enthalpies $=\quad-355.741999$

Sum of electronic and thermal Free Energies $=\quad-355.781575$

\section{Pd0_sp2_TS}

Number of imaginary frequencies : 1

The smallest frequencies are : -490.6937 $7.071027 .5754 \mathrm{~cm}(-1)$

Electronic energy : $\quad=-627.3696036$

Zero-point correction $=\quad 0.186546$

Thermal correction to Energy= $\quad 0.200719$

Thermal correction to Enthalpy= $\quad 0.201664$

Thermal correction to Gibbs Free Energy $=0.139976$

Sum of electronic and zero-point Energies $=\quad-627.183058$

Sum of electronic and thermal Energies $=\quad-627.168884$

Sum of electronic and thermal Enthalpies $=\quad-627.167940$

Sum of electronic and thermal Free Energies $=\quad-627.229628$

Pd0_sp2_product 
Number of imaginary frequencies : 0

Electronic energy : $\quad=-627.3759033$

Zero-point correction $=\quad 0.186923$

Thermal correction to Energy $=\quad 0.201631$

Thermal correction to Enthalpy= $\quad 0.202575$

Thermal correction to Gibbs Free Energy $=0.140436$

Sum of electronic and zero-point Energies $=\quad-627.188981$

Sum of electronic and thermal Energies $=\quad-627.174273$

Sum of electronic and thermal Enthalpies $=\quad-627.173328$

Sum of electronic and thermal Free Energies $=\quad-627.235467$

Pd0_sp3_TS

Number of imaginary frequencies : 1

The smallest frequencies are : -818.1170 $15.238525 .6434 \mathrm{~cm}(-1)$

Electronic energy : $\quad=-627.370608$

Zero-point correction $=\quad 0.186832$

Thermal correction to Energy= $\quad 0.200563$

Thermal correction to Enthalpy $=\quad 0.201507$

Thermal correction to Gibbs Free Energy $=0.141903$

Sum of electronic and zero-point Energies $=\quad-627.183776$

Sum of electronic and thermal Energies $=\quad-627.170045$

Sum of electronic and thermal Enthalpies $=\quad-627.169101$

Sum of electronic and thermal Free Energies $=\quad-627.228705$

Pd0_sp3_product

Number of imaginary frequencies : 0

Electronic energy: $\quad=-627.3846065$

Zero-point correction $=\quad 0.187870$

Thermal correction to Energy $=\quad 0.201648$

Thermal correction to Enthalpy $=\quad 0.202592$

Thermal correction to Gibbs Free Energy $=0.142913$

Sum of electronic and zero-point Energies $=\quad-627.196736$

Sum of electronic and thermal Energies $=\quad-627.182959$

Sum of electronic and thermal Enthalpies $=\quad-627.182015$

Sum of electronic and thermal Free Energies $=\quad-627.241694$ 
Number of imaginary frequencies : 0

Electronic energy: $\quad=-584.3105232$

Zero-point correction $=\quad 0.113851$

Thermal correction to Energy= $\quad 0.126226$

Thermal correction to Enthalpy= $\quad 0.127170$

Thermal correction to Gibbs Free Energy $=0.069745$

Sum of electronic and zero-point Energies $=\quad-584.196672$

Sum of electronic and thermal Energies $=\quad-584.184297$

Sum of electronic and thermal Enthalpies $=\quad-584.183353$

Sum of electronic and thermal Free Energies $=\quad-584.240778$

Pd1_sp2_TS

Number of imaginary frequencies : 1

The smallest frequencies are : -1149.1820 $20.265923 .2125 \mathrm{~cm}(-1)$

Electronic energy: $\quad=-855.8675306$

Zero-point correction $=\quad 0.238635$

Thermal correction to Energy $=\quad 0.258076$

Thermal correction to Enthalpy= $\quad 0.259021$

Thermal correction to Gibbs Free Energy $=0.184405$

Sum of electronic and zero-point Energies $=\quad-855.628895$

Sum of electronic and thermal Energies $=\quad-855.609454$

Sum of electronic and thermal Enthalpies $=\quad-855.608510$

Sum of electronic and thermal Free Energies= $\quad-855.683126$

\section{Pd1_sp2_product}

Number of imaginary frequencies : 0

Electronic energy : $\quad=-855.8759928$

Zero-point correction $=\quad 0.243524$

Thermal correction to Energy $=\quad 0.263826$

Thermal correction to Enthalpy= 0.264771

Thermal correction to Gibbs Free Energy $=0.186262$

Sum of electronic and zero-point Energies $=\quad-855.632468$

Sum of electronic and thermal Energies $=\quad-855.612166$

Sum of electronic and thermal Enthalpies $=\quad-855.611222$

Sum of electronic and thermal Free Energies $=\quad-855.689731$ 


\section{Pd1_sp3_TS}

Number of imaginary frequencies : 1

The smallest frequencies are : -1349.6960 $9.708520 .6421 \mathrm{~cm}(-1)$

Electronic energy : $\quad=-855.8636037$

Zero-point correction $=\quad 0.238375$

Thermal correction to Energy= $\quad 0.257377$

Thermal correction to Enthalpy= $\quad 0.258321$

Thermal correction to Gibbs Free Energy $=0.184529$

Sum of electronic and zero-point Energies $=\quad-855.625229$

Sum of electronic and thermal Energies $=\quad-855.606227$

Sum of electronic and thermal Enthalpies $=\quad-855.605283$

Sum of electronic and thermal Free Energies $=\quad-855.679075$

Pd1_sp3_product

Number of imaginary frequencies : 0

Electronic energy : $\quad=-855.877054$

Zero-point correction $=\quad 0.243170$

Thermal correction to Energy $=\quad 0.262974$

Thermal correction to Enthalpy= $\quad 0.263918$

Thermal correction to Gibbs Free Energy $=0.186125$

Sum of electronic and zero-point Energies $=\quad-855.633884$

Sum of electronic and thermal Energies $=\quad-855.614080$

Sum of electronic and thermal Enthalpies $=\quad-855.613136$

Sum of electronic and thermal Free Energies $=\quad-855.690929$

Pd2_2-OAc

Number of imaginary frequencies : 0

Electronic energy : $\quad=-583.7292813$

Zero-point correction $=\quad 0.103571$

Thermal correction to Energy= $\quad 0.114377$

Thermal correction to Enthalpy= $\quad 0.115321$

Thermal correction to Gibbs Free Energy $=0.064113$

Sum of electronic and zero-point Energies $=\quad-583.625710$

Sum of electronic and thermal Energies $=\quad-583.614905$ 
Sum of electronic and thermal Enthalpies=

$-583.613961$

Sum of electronic and thermal Free Energies=

$-583.665168$

Pd2_sp2-TS

Number of imaginary frequencies : 1

The smallest frequencies are : -1058.0164 9.2922 $18.4471 \mathrm{~cm}(-1)$

Electronic energy: $\quad=-855.2669752$

Zero-point correction $=\quad 0.227563$

Thermal correction to Energy= $\quad 0.246017$

Thermal correction to Enthalpy= $\quad 0.246961$

Thermal correction to Gibbs Free Energy= $\quad 0.175045$

Sum of electronic and zero-point Energies $=\quad-855.039412$

Sum of electronic and thermal Energies $=\quad-855.020958$

Sum of electronic and thermal Enthalpies $=\quad-855.020014$

Sum of electronic and thermal Free Energies $=\quad-855.091930$

Pd2_sp2_product

Number of imaginary frequencies : 0

Electronic energy: $\quad=-855.2888341$

Zero-point correction $=\quad 0.233093$

Thermal correction to Energy= $\quad 0.252059$

Thermal correction to Enthalpy= $\quad 0.253003$

Thermal correction to Gibbs Free Energy $=0.181293$

Sum of electronic and zero-point Energies $=\quad-855.055741$

Sum of electronic and thermal Energies $=\quad-855.036775$

Sum of electronic and thermal Enthalpies $=\quad-855.035831$

Sum of electronic and thermal Free Energies $=\quad-855.107541$

Pd2_sp3_TS

Number of imaginary frequencies : 1

The smallest frequencies are : -1109.6848 $18.944534 .6548 \mathrm{~cm}(-1)$

Electronic energy: $\quad=-855.2452966$

Zero-point correction $=\quad 0.227940$

Thermal correction to Energy= $\quad 0.245833$

Thermal correction to Enthalpy $=\quad 0.246777$ 
Thermal correction to Gibbs Free Energy=

Sum of electronic and zero-point Energies=

Sum of electronic and thermal Energies=

Sum of electronic and thermal Enthalpies=

Sum of electronic and thermal Free Energies=
0.178478

$-855.017357$

$-854.999464$

$-854.998519$

$-855.066818$

Pd2_sp3_product

Number of imaginary frequencies : 0

Electronic energy: $\quad=-855.3013985$

Zero-point correction $=\quad 0.232566$

Thermal correction to Energy= $\quad 0.250877$

Thermal correction to Enthalpy $=\quad 0.251821$

Thermal correction to Gibbs Free Energy $=0.182325$

Sum of electronic and zero-point Energies $=\quad-855.068833$

Sum of electronic and thermal Energies $=\quad-855.050522$

Sum of electronic and thermal Enthalpies $=\quad-855.049578$

Sum of electronic and thermal Free Energies $=\quad-855.119074$

\section{Pd3_3-OAc}

Number of imaginary frequencies : 0

Electronic energy : $\quad=-812.1736445$

Zero-point correction $=\quad 0.154583$

Thermal correction to Energy= $\quad 0.170969$

Thermal correction to Enthalpy $=\quad 0.171913$

Thermal correction to Gibbs Free Energy $=0.106001$

Sum of electronic and zero-point Energies= $\quad-812.019061$

Sum of electronic and thermal Energies $=\quad-812.002675$

Sum of electronic and thermal Enthalpies $=\quad-812.001731$

Sum of electronic and thermal Free Energies $=\quad-812.067643$

\section{Pd3_sp2_TS}

Number of imaginary frequencies : 1

The smallest frequencies are : -793.9776 $13.430433 .3719 \mathrm{~cm}(-1)$

Electronic energy: $\quad=-1083.696752$

Zero-point correction $=\quad 0.278650$ 
Thermal correction to Energy=

Thermal correction to Enthalpy=

Thermal correction to Gibbs Free Energy=

Sum of electronic and zero-point Energies=

Sum of electronic and thermal Energies=

Sum of electronic and thermal Enthalpies=

Sum of electronic and thermal Free Energies=
0.302525

0.303469

0.220054

$-1083.418102$

$-1083.394227$

$-1083.393283$

$-1083.476698$

Pd3_sp2_product

Number of imaginary frequencies : 0

Electronic energy : $\quad=-1083.7565248$

Zero-point correction $=\quad 0.284302$

Thermal correction to Energy $=\quad 0.308782$

Thermal correction to Enthalpy= $\quad 0.309726$

Thermal correction to Gibbs Free Energy $=\quad 0.223687$

Sum of electronic and zero-point Energies $=\quad-1083.472223$

Sum of electronic and thermal Energies $=\quad-1083.447743$

Sum of electronic and thermal Enthalpies= $\quad-1083.446799$

Sum of electronic and thermal Free Energies $=\quad-1083.532838$

Pd3_sp3_TS

Number of imaginary frequencies : 1

The smallest frequencies are : -1003.2784 $25.715235 .5991 \mathrm{~cm}(-1)$

Electronic energy : $\quad=-1083.6828546$

Zero-point correction $=\quad 0.278905$

Thermal correction to Energy= $\quad 0.302315$

Thermal correction to Enthalpy $=\quad 0.303259$

Thermal correction to Gibbs Free Energy $=0.221941$

Sum of electronic and zero-point Energies $=\quad-1083.403950$

Sum of electronic and thermal Energies $=\quad-1083.380540$

Sum of electronic and thermal Enthalpies $=\quad-1083.379596$

Sum of electronic and thermal Free Energies $=\quad-1083.460914$

Pd3_sp3_product

Number of imaginary frequencies : 0 
Electronic energy: $\quad=-1083.7702848$

Zero-point correction= 0.285544

Thermal correction to Energy= 0.309478 Thermal correction to Enthalpy= 0.310422

Thermal correction to Gibbs Free Energy= Sum of electronic and zero-point Energies= Sum of electronic and thermal Energies= Sum of electronic and thermal Enthalpies= Sum of electronic and thermal Free Energies= 0.226379 $-1083.484740$ $-1083.460807$ $-1083.459863$ $-1083.543906$ 